\title{
Bases históricas para la reforma del proceso laboral
}

\author{
Jaime Alemañ Cano \\ Profesor Titular doctor de EU \\ Universidad de Alicante
}

Recibido: 09.02.09

Aceptado: 04.05.09

\begin{abstract}
Resumen: El proceso laboral está necesitado de una profunda reforma. A esta reforma solo se puede llegar por una de estas dos vías: o bien a través de la sustitución de la actual ley por otra adaptada perfectamente a la Ley de Enjuiciamiento Civil, o bien mediante la derogación de la vigente norma procesal y la integración del proceso laboral en la ley adjetiva civil. A esta dual conclusión se llega en el presente artículo donde se estudia, de manera sucinta, el desarrollo histórico del proceso laboral, y en el cual se aprecia la íntima atracción existente entre ambas normas procesales. En el actual estudio, se enfatiza con más fuerza el criterio de la integración porque ello supondría la eliminación de un gran número de los procesos especiales en vigor. De cualquier manera, la reforma debe producirse con el fin de obtener las máximas garantías para el justiciable y para, en definitiva, alcanzar una mayor tutela judicial efectiva como derecho fundamental consagrado en la Constitución Española de 1978.

Palabras clave: historia del proceso laboral español; eventual reforma del proceso laboral; mejora del derecho fundamental a la tutela judicial efectiva.

Abstract: The work process is in need of profound reform. This reform can only be reached by one of two ways: either by replacing the current law for another perfectly suited to the Code of Civil Procedure or by the repeal of the existing procedural rules and the integration of labor process in the civil law adjectival. This dual conclusion can be reached in this article which examines, in brief, the historical development of the labor process, and which appreciates the intimate attraction between the two procedural rules. In the current study, it emphasizes more strongly the test of integration because it would mean the elimination of a large number of special processes in place. Either way, the reform must occur in order to obtain maximum guarantees for the individual and, ultimately, achieve greater effective remedy as a fundamental right enshrined in the Spanish Constitution of 1978.
\end{abstract}

Key words: history of the labour process in Spain; possible reform of the labour process; improving the fundamental right to achieve greater effective remedy.

Sumario: I. Introducción.--II. El andamiaje del proceso laboral.III. Perfiles orgánicos para un proceso laboral.-IV. El nuevo escenario procesal inaugurado en 1958. - V. La necesaria reordenación del proceso laboral. 


\section{Introducción}

La historia de las Instituciones, olvidada o denostada en muchas ocasiones, puede ofrecer, aunque parezca inverosímil, una visión dinámica del Derecho actual o, como en el presente caso, una orientación de cómo debería plantearse el legislador las futuras reformas. El auxilio al método histórico, consecuentemente, permite conocer cómo ha nacido y se ha desarrollado el Derecho; y dentro del método, la orientación institucional va a posibilitar el análisis de las dificultades encontradas en la aplicación del Derecho, el desvanecimiento de tales dificultades, y la generación de otras nuevas ${ }^{1}$.

El análisis de los antecedentes del proceso laboral debería ofrecer, al menos, un recorrido histórico desde el momento mismo del arraigo del Derecho romano en sede peninsular hasta la recepción de las primeras leyes de enjuiciamiento. Sin embargo, tan pretenciosa investigación rebasaría con mucho los límites del actual estudio, pues requeriría, además, de un pormenorizado examen no solo jurídico sino también socioeconómico de dos largos períodos históricos como lo son las Edades Media y Moderna.

La historia del proceso laboral se encuentra, pues, por elaborar desde diferentes perspectivas y no solo desde la jurídico-científica, aunque las limitaciones aquí impuestas no han de impedir anotar alguna reseña, aun por escasa indagación, de aquellos tiempos opacos donde un embrionario proceso laboral parecía encontrarse latente.

Los escuetos períodos históricos plasmados en las siguientes páginas pretenden poner al descubierto, sobre la base de las instituciones involucradas en cada momento, las fases por las cuales ha transcurrido el proceso laboral, tosco en sus inicios, pero maduro y perfectamente asentado en el ordenamiento de los últimos tiempos. Pero también, tales períodos históricos van a permitir poner al descubierto las carencias actuales frente a las cuales la retrospectiva puede ofrecer las claves para diseñar un proceso más garantizador de los derechos involucrados.

\section{EI andamiaje del proceso laboral}

En verdad, cabría preguntarse si sería posible referirse a un proceso laboral previo a la recepción protagonizada en el siglo XIX por las primeras leyes de enjuiciamiento civil, o si, por el contrario, tal referencia vendría a ser excesivamente forzada si se atiende al sincronismo entre la aparición del Derecho del Trabajo y las correspondientes normas formales.

La literatura jurídica de las primeras décadas de la pasada centuria solía incorporar alguna breve acotación o aproximación al Derecho primitivo y al

${ }^{1}$ García-Gallo, A. El origen y la evolución del Derecho. Manual de historia del Derecho español I. Artes Gráficas y Ediciones, S.A. Octava edición. Madrid, 1979, págs. 16-18. 
Derecho del medioevo relacionada con el proceso laboral, aunque tal relación se situaba más bien en la acomodación de determinadas instituciones de naturaleza «arrendaticia» a los procesos vigentes en cada momento y en tanto en cuanto se producía la quiebra o el incumplimiento de las partes implicadas de las respectivas obligaciones contraídas. En esta línea de aportación doctrinal, solía distinguirse entre los antecedentes situados en el Derecho romano de aquellos otros localizados, principalmente, en las cofradías medievales.

La institución por excelencia arraigada en la Iberia romana venía representada por los denominados Colegios, los cuales llegaron a implantar, incluso, auténticas condiciones de trabajo como la relativa a la fijación de escalas salariales ${ }^{2}$. Los citados Colegios constituían asociaciones de variada estructura, tales como las sociedades de los arrendatarios de impuestos, la de los contratistas de obras públicas, así como una larga serie de institutos conocidos como los gremios, las hermandades, los sindicatos de artesanos, las sociedades de culto, los colegios funerarios, etc. La remuneración de los trabajadores manuales y jornaleros durante la República y, más tarde, el pago de honorarios a los médicos, abogados y maestros ya en la época Imperial, podía reclamarse judicialmente a través del llamado procedimiento extraordinaria cognitio ${ }^{3}$.

La desaparición del imperio romano no vino a suponer la extinción inmediata de sus instituciones; antes al contrario ${ }^{4}$, pues tales instituciones continuaron prevaleciendo durante toda la Edad Media aunque, ello sí, con una clara y progresiva asfixia de sus instrumentos jurídicos reguladores ${ }^{5}$. Consecuentemente, la organización del trabajo y las leyes romanas persistieron en la época visigoda (siglo $\mathrm{V}$ y comienzos del VIII). Y es, precisamente, con la decadencia del reinado visigótico cuando, en puridad, puede hablarse de un vacío legislativo hasta el siglo XII, en definitiva, el nacimiento de la «cofradía», el «gremio» y el «oficio» medievales, de meridiano parentesco con las «gildas» germanas ${ }^{6}$. En estas últimas, y por extensión en aquellas otras aquí arraigadas, la solución a las cuestiones y conflictos surgidos se saldaba mediante fórmulas de naturaleza autocompositiva, como lo era el sometimiento de sus componentes a arbitraje y ante la comunidad ${ }^{7}$. Los gremios -cabría argumentar de manera muy generalizada- se erigieron

\footnotetext{
${ }^{2}$ MenéndeZ-Pidal, J. Derecho procesal social. EDERSA. Madrid, 1950, pág. 17.

3 JöRs, P. y KunKel, W. Derecho privado romano. Traducción de L. Prieto Castor. Labor. Barcelona, 1965, págs. 106 y 323.

${ }^{4}$ Justiniano. Corpus Iuris Civiles. Weidemann. Dublin/Zürich, 1973, Tomo I, pág. 289 (38), y Tomo II, pág. 418 (XXXVII-1).

${ }^{5}$ Arias Ramos, J. y Arias Bonet, J. A. Derecho romano. Tomo I. EDERSA, 15. ${ }^{\text {e edi- }}$ ción. Madrid, 1979, págs. 3-4.

${ }^{6}$ Rumeu de Armas, A. Historia de la previsión social en España (Cofradías, Gremios, Hermandades y Montepíos). Ediciones El Albir. Barcelona, 1981, págs. 27-34.

${ }^{7}$ MenÉndEZ-PIDAL, J. «Derecho procesal social...», cit., págs. 17-18.
} 
en autoridad («Comisiones» y «Juntas Gremiales») para dirimir las controversias surgidas entre sus miembros, si bien ello no impedía la reclamación de salarios ante los corregidores o las Chancillerías ${ }^{8}$.

No obstante la aludida generalización, esta carecería de rigor histórico y científico si dejara de realizarse alguna matización. Con este alcance, y en la baja Edad Media, organizada principalmente bajo las cofradías, aparecía una autoridad, un cuerpo deliberante y un cuerpo judicial («amigables componedores»), entendido este último como sistema administrativo y financiero para asegurar la vida y fines de la entidad, pero carente de poder jurisdiccional en sentido estricto. Con los gremios, y ya en la Edad Moderna, los Municipios y los Corregidores -pese al interés del Poder real por centralizar las facultades jurisdiccionales- eran los encargados de resolver, sobre todo en Valencia y Barcelona, los litigios surgidos de la interpretación de las respectivas ordenanzas, salvo cuando tales litigios surgían entre un mismo gremio, en cuyo caso el Consejo Real los podía revocar. Esta última situación se vino a mantener con mayores o menores variables hasta el siglo XVIII, hasta la desaparición, en las regiones de la Corona de Aragón, del régimen foral sustituido este por el modelo centralista francés impuesto por Felipe V. Las potestades de los antiguos Concelleres para conocer y fallar las causas de los gremios recayeron, consecuentemente y con criterio general, en el Corregidor y en la Real Audiencia9.

El declive de la actividad gremial, cuyas causas, indudablemente, no pueden manifestarse en extenso en este lugar, aunque sí apuntarlas, vino a suponer el inicio de un profundo cambio orientado hacia el nuevo marco legal de unas incipientes relaciones laborales. Tales causas de extinción de los gremios derivarían, por un lado, de las luchas intestinas de los propios gremios. Pero, principalmente, y en segundo término, la citada extinción apuntaría más en el acaecimiento de la revolución industrial a raíz de la aparición de las primeras máquinas (siglo XVIII), si bien, y en lo tocante a España, dicho acaecimiento no tuvo lugar sino hasta bien entrado el primer cuarto del siglo XIX; un desarrollo industrial este compaginado, además, por la superación del mercantilismo-colbertismo en favor de las doctrinas fisiocráticas y la trascendental construcción individualista de Adam Smith y sus seguidores ${ }^{10}$.

\footnotetext{
${ }^{8}$ Bayón Chacón, G. y PéRez Botija, E. Manual de Derecho del Trabajo. Volumen II. Marcial Pons, séptima edición. Madrid, 1967, págs. 873-874.

${ }^{9}$ Rumeu De ARmas, A. «Historia de la previsión social en España..., cit., págs. 120 y 122,188 y 189, y 321 y 322.

${ }^{10}$ De la Villa Gil, L. E. La formación histórica del Derecho Español del Trabajo. Comares. Granada, 2003, págs. 50-52.
} 
La abolición del monopolio gremial a través del Decreto de 1813, del conde Toreno $^{11}$, conllevó, entre otras cosas, un vacío legislativo de la recién, aunque incipiente, actividad laboral. Cabría preguntarse, entonces, cómo y durante cuánto tiempo vino a colmarse dicho vacío.

El citado vacío se prolongó desde 1813 hasta los años previos a la entrada en vigor del Código Civil (1889). Durante dicho período fueron dos cuerpos normativos llamados a colmar el hueco normativo dejado por la desaparición de la legislación reguladora de los gremios. Por un lado, el Título III y siguientes del Libro XI de la Novísima Recopilación ${ }^{12}$. Por otro lado, aunque con distinto rango legal, el Título II de la Partida 3. ${ }^{a}$ del Código alfonsino $^{13}$. Finalmente, ciertos Fueros, como el de Navarra ${ }^{14}$, vinieron a completar tan exigua cimentación legislativa, tal y como ponen de manifiesto los primeros comentaristas decimonónicos del Código Civil ${ }^{15}$.

Este amplio espacio temporal de más de setenta años (1813-1889) puede subdividirse artificialmente en tres períodos donde se va a poder apreciar el conjunto de normas -sustantivas y procesales- aprobadas en diferentes fases y por diferentes gobiernos, cuyo fin era dar respuesta, aunque liviana, a las demandas sociales provenientes de un recién nacido movimiento laboral.

El primer período es el comprendido entre el Decreto Toreno (1813) y la primera Ley de Enjuiciamiento Civil (1855). En él ven la luz, entre otras muchas normas, el Decreto de 8 de junio de 1813, sobre libertad de industrias y oficios; la Real Orden de 24 de junio de 1824, de promoción del uso de las máquinas en las fábricas; el Código de Comercio de 3 de junio de 1829; la Real Orden de 28 de febrero de 1839, sobre autorización y fomento de la Sociedades de Socorros Mutuos ${ }^{16}$; el significativo Bando del Jefe

${ }^{11}$ Sala Franco, T. y López Gandía, J. et alii, Derecho del Trabajo. Tomo I. Fuentes y relaciones colectivas. Tirant lo blanch, 7. a edición. Valencia, 2005, págs. 35-36.

12 Martín Valverde, A. «La formación del Derecho del Trabajo en España», en La Legislación social en la historia de España. De la revolución liberal a 1936. Congreso de los Diputados. Madrid, 1987, págs. XIX, XXIII y XXXII. Vide Crónica de la Codificación, 2. Procedimiento civil. Ministerio de Justicia. Comisión General de Codificación. Madrid, 1970 , pág. 1.

${ }^{13}$ Sobre la aplicación de las Partidas, vide «Arrendamiento de trabajo personal» con la jurisprudencia del Tribunal Supremo de Justicia, en SÁEnz Hérmua y EsPinosa, P. Diccionario recopilador de los Puntos de Derecho. Tipografía de Manuel G. Hernández, tomo primero. Madrid, 1884, págs. 59-60.

${ }^{14}$ Gómez de la Serna, P. y Montalbán, J. M. Elementos de Derecho civil y penal de España. Tomo segundo. A. Peñuelas. Madrid, 1869, pág. 314.

${ }^{15}$ Vide Bofarull, M. de, Código Civil Español, según la edición oficial, anotado y concordado con la anterior legislación y jurisprudencia española y los códigos extranjeros. Imprenta de Antonio Pérez Dubrull, primera edición, Madrid, 1888, pág. 496.

${ }^{16}$ Real Orden, por otro lado, suspendida por la también Real Orden de 25 de agosto de 1853, de aplicación de las disposiciones sobre compañías mercantiles por acciones. 
Político de Barcelona, de 22 de mayo de 1840, en el cual se establecen condiciones de trabajo en las fábricas del sector textil y la creación de una Comisión Inspectora ${ }^{17}$; finalmente, cabe señalar el Bando del Capitán General de Cataluña, de 9 de junio de 1854, a través del cual se aprueban las Bases para la constitución de un Tribunal para dirimir las cuestiones planteadas entre fabricantes y operarios.

El segundo de los períodos citados se abre en el año 1855 con la aprobación de la primera Ley de Enjuiciamiento Civil ${ }^{18}$, y discurre hasta el año 1881 con la derogación de aquella y la promulgación de la segunda ley formal civil, la de 3 de febrero de 1881. En este período, acaecen normas de suma trascendencia en la disciplina laboral, tanto sustantivas como adjetivas. En este sentido, destacan la Ley de Organización Provisional del Poder Judicial, de 15 de septiembre de 1870; la Circular del Ministerio de Gobernación de 16 de enero de 1872, sobre tratamiento de la cuestión social; la Ley de 24 de julio de 1873, sobre condiciones de trabajo en las fábricas, talleres y minas; el Proyecto de Ley, de 14 de agosto de 1873, sobre Jurados Mixtos, en el mismo año de instauración de la primera República ${ }^{19}$; y la Ley de 26 de julio de 1878 , sobre trabajos peligrosos para los niños.

Por último, el tercero de los períodos arranca con la expresada Ley de Enjuiciamiento Civil de 1881 y finaliza en 1889, fecha de la entrada en vigor del Código Civil, donde se vislumbraba el primer atisbo de una primigenia relación laboral (contrato de arrendamiento de servicios). En este período destacan, entre otras normas, el Real Decreto de 5 de diciembre de 1883, de creación de la Comisión de Reformas Sociales; la Real Orden de 18 de mayo de 1884, de constitución de Comisiones Provinciales y Locales de Reformas Sociales; el Código de Comercio de 22 de agosto de 1885; la Ley de Asociaciones, de 30 de junio de 1887; y la Real Orden de 8 de octubre de 1888, sobre el ejercicio del derecho de reunión.

Esta amalgama de normas, en muchas ocasiones supresoras y suspensivas las unas de las otras sin solución de continuidad, y de las cuales se ha ofrecido una breve descripción en su número y en su contenido, produjo, como no podía ser de otra manera, una gran inseguridad jurídica. Unas, las sustantivas, porque no tenían apoyo en las adjetivas; otras, las procesales, porque no conseguían dar respuesta a las necesidades de una actividad, la emanada de las nuevas fábricas e industrias, tan necesitada por dar pronta

${ }^{17}$ En idéntico sentido, la Circular del mismo órgano político, de 21 de octubre de 1844 , sobre condiciones de trabajo en las fábricas del sector textil y constitución de una Junta para dirimir las cuestiones suscitadas entre fabricantes y operarios.

${ }^{18}$ En el año 1830 ve la luz la Ley de Enjuiciamiento Mercantil.

${ }^{19}$ También el año 1873 fue proclive a la creación local -Cádiz y Alcoy- de organismos paritarios para la solución de conflictos de trabajo, aunque los resultados fueron más bien baldíos (cfr. MenÉndeZ-PidAl, J. Derecho social español, Volumen I, EDERSA, Madrid, 1952, págs. 50 y ss.). 
solución a los problemas surgidos entre patronos y obreros -conflictosacaecidos en la larga época reseñada.

La caótica y oscura situación descrita empieza a desvanecerse en el tercero de los períodos anotados, por cuanto las reclamaciones judiciales provenientes de las relaciones laborales van a ser competencia de los tribunales ordinarios civiles, los cuales conocerán de las pretensiones derivadas de dichas relaciones a través de los procesos ordinarios en función de la cuantía del asunto. Sin embargo, los tribunales civiles pronto se mostraron insatisfactorios, y la clase obrera, desde mediados del siglo XIX, reclamó la creación de órganos paritarios capaces de resolver las diferencias existentes con los patronos; una clase trabajadora hastiada, como lo estaba, de resolver las controversias a través de un sistema judicial cuyas raíces debían buscarse en las Partidas, y en un proceso con la impronta liberal e individualista imperante, y cuyas características más acusadas eran lentitud y carestía ${ }^{20}$.

Más tarde, en 1891 y ya fuera de los períodos descritos, tiene lugar un intento por establecer tribunales de trabajo. A tal fin, la Comisión de Reformas Sociales elaboró un proyecto encomendado nueve años atrás. El Proyecto creaba los que llamaba Jurados Industriales, formados por un presidente $y$ vocales patronos y obreros, actuando el pleno en tres secciones: Delegación Tutelar, Mesa de Conciliación y Sala Jurisdiccional. En el mismo año se presentaron a la Comisión otros dos proyectos que establecían, respectivamente, Juntas Mixtas de Consulta y Arbitraje y Jurados Mixtos Arbitra$l e s^{21}$.

Sin embargo, va a ser en el año 1900, con la Ley de Accidentes de trabajo de 30 de enero, cuando se va a iniciar en verdad el despegue tan necesitado y reclamado por la sociedad. La expresada ley, aun cuando anunció el establecimiento de una jurisdicción especial cuyo objeto sería la resolución de conflictos suscitados con motivo de su aplicación, atribuyó, por de pronto, su conocimiento al juez de primera instancia por el procedimiento del «juicio verbal»22; esto es, por el procedimiento más rápido y sencillo de la $L E C$, pero manteniendo todo su sistema, incluidos los recursos ${ }^{23}$.

\section{Perfiles orgánicos para un proceso laboral}

A la vista de la sintética exposición normativa anteriormente referida, el proceso del trabajo resulta de la aplicación de las normas del proceso civil

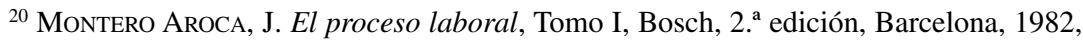
pág. 34.

${ }^{21}$ Hernáinz Márquez, M. Tratado elemental de Derecho del Trabajo. Instituto de Estu-

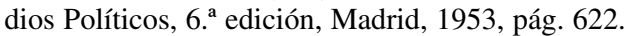

${ }^{22}$ De la Plaza, M. Derecho procesal civil español, Volumen II, Primera parte, EDERSA, Madrid, 1955, pág. 436.

${ }^{23}$ Montero Aroca, J. El proceso laboral..., cit., Tomo I, pág. 34. 
ordinario a las exigencias y problemas peculiares del mundo de la producción y el trabajo, y para aplacar, en alguna medida, los conflictos laborales y también reforzar notablemente el cumplimiento de la normativa en la materia.

La auténtica conversión de uno en otro proceso se produce con la Ley de 19 de mayo de 1908, de Tribunales Industriales ${ }^{24}$. La expresada ley ha de ser analizada desde la perspectiva histórica ofrecida por dos importantes reformas: a) la Ley de 22 de julio de 1912, germen del actual proceso laboral ${ }^{25}$, y por la cual se inició el régimen de jurisdicción especial mixta para la solución de los conflictos individuales de trabajo a imitación de otras legislaciones europeas (Alemania, Austria, Bélgica e Italia) ${ }^{26}$; y b) por el Real Decreto Ley de 23 de agosto de 1926, de Código de Trabajo ${ }^{27}$. Estos Tribunales estaban compuestos por un juez de primera instancia, presidente, y de dos jurados y un suplente, patronos, y dos jurados y un suplente, obreros. Los jurados conocían de los hechos y emitían un veredicto, si bien se reservaba al juez la aplicación del derecho sobre los citados hechos y la elaboración de la sentencia. La resolución dictada era susceptible de ser recurrida en revisión ante la Audiencia Territorial, o bien cabía contra ella recurso de casación ante el Tribunal Supremo, cuya Sala de lo Social se creó en $1931^{28}$.

El conjunto normativo anteriormente referido convivió con la Ley de Jurados Mixtos Profesionales de 27 de noviembre de $1931^{29}$. Tales Jurados, a diferencia de los Tribunales Industriales, y aunque estaban constituidos por un presidente y vocales patronos y obreros, no eran órganos jurisdiccionales, sino órganos de naturaleza administrativa.

La convivencia entre los Jurados Mixtos y los Tribunales Industriales conllevó una competencia dual en el tratamiento de la problemática laboral, pues mientras los primeros conocían de los litigios sobre pagos de salarios, horas extraordinarias, despido y los análogos derivados del cumplimiento del contrato de trabajo, los Tribunales Industriales atendían, principalmente, a materias concernientes a accidentes de trabajo. Este desdoblamiento compe-

\footnotetext{
${ }^{24}$ Martín Valverde, A. La formación del Derecho del Trabajo en España..., cit., págs. XXX y XXXI, y LVII y LVIII.

${ }^{25}$ Montero Aroca, J. El proceso laboral..., cit., Tomo I, pág. 35.

${ }^{26}$ Miguel y Romero, M. Derecho procesal teórico (Procedimientos judiciales), Tomo I, Librería General de Victorino Suárez, Madrid, 1934, págs. 232-233.

${ }^{27}$ Artículos 487 y siguientes de dicho Código.

${ }^{28}$ Montero Aroca, J. El proceso laboral..., cit., Tomo I, pág. 35.

${ }^{29}$ Incluidos el Real Decreto-ley de 9 de diciembre, y el Real Decreto de 8 de marzo de 1929, ambos sobre Organización Corporativa Nacional. Vide De la PlazA, M. Derecho procesal civil español..., cit., Volumen II, Primera parte, pág. 436; AGUILERA DE PAZ, E. y Rives Y MARTí, F. Derecho judicial español. T. I. Reus. Madrid, 1920, págs. 276-277; GALLART FolCH, A. Derecho español del trabajo. Labor. Barcelona, 1936, págs. 324 y ss; y, finalmente, Crónica de la codificación española. 1. Organización judicial..., cit., pág. 339.
} 
tencial se mantuvo hasta la promulgación de la Ley de 16 de julio de 1935, de Régimen de los Jurados Mixtos y supresión de los Tribunales Industriales, aunque no llegó a tener efectividad práctica al ser derogada, poco tiempo después, por la Ley de 30 de mayo de 1936, de derogación de la Ley de 1935 y el restablecimiento de la Ley de $1931^{30}$.

El lamentable período de la guerra civil supuso, en el ámbito del proceso laboral, por un lado, la distinta aplicación de normas -derogación de unas y creación de otras, o mantenimiento de las existentes-en función de la zona geográfica donde tales normas intentaran hacerse efectivas. Pero, por otro lado, la citada contienda bélica y la solución final alcanzada supusieron la estigmatización de los órganos jurisdiccionales precedentes y su sustitución por otros de remarcada verticalidad con un poder ejecutivo consolidado a lo largo de las cuatro décadas siguientes.

Así, el 5 de noviembre de 1936, se produce la supresión por Queipo de Llano de los Jurados Mixtos en Andalucía, si bien seguirían con sus atribuciones los Tribunales Industriales. Sin embargo, el Fuero del Trabajo, de 9 de marzo de 1938 (Declaración VII), vino a anunciar la creación ex novo de la denominada «Magistratura de Trabajo», y ello desembocaría, poco después, en la supresión de aquellos Jurados y Tribunales por la Ley de 17 de octubre de 1940, Orgánica de las Magistraturas de Trabajo, la cual no solo desarrolló esta última institución, sino también creó el Tribunal Central de Trabajo $^{31}$. Es de destacar, y a propósito del verticalismo antes referido, la nada casual vinculación administrativa de las recién inauguradas Magistraturas con el Ministerio de Trabajo, tal y como se evidencia en los artículos sexto y séptimo, y en la disposición final de la expresada ley.

Con todo, empresario y trabajadores tuvieron que ceder su autonomía a un Estado que intentó controlar hasta $1958^{32}$ incluso los aspectos más insignificantes del mundo laboral ${ }^{33}$. El expresado control alcanzó, obviamente, al campo del derecho procesal laboral. Desde la finalización de la contienda hasta la promulgación de la primera ley formal social en 1958, y aun mucho después, se atravesó por un período caracterizado por una creación legislativa represiva y doctrinaria - pero al mismo tiempo excesivamente proteccionista del trabajador- diseñada mediante mecanismos jurídicos impuestos de manera interesada por un sistema más preocupado en enaltecer su ideario que en procurar el bienestar social de sus obligados correligionarios.

${ }^{30}$ Vide Hernáinz Márquez, M. Tratado elemental de Derecho del Trabajo..., cit., pág. 623. Vide Gallart Folch, A. Derecho español del Trabajo..., cit., págs. 327 y ss.

${ }^{31}$ Bayón Chacón, G. y Pérez Botija, E. Manual de Derecho del Trabajo..., cit., Volumen II, pág. 876.

${ }^{32}$ Fecha de aprobación de la Ley de Convenios Colectivos.

${ }^{33}$ AizPuru, M. y Rivera, A. Manual de historia social del trabajo. Siglo Veintiuno Editores, Madrid, 1994, págs. 341-342. 


\section{El nuevo escenario procesal inaugurado en 1958}

La Ley de 24 de abril de 1958 se erigió en la primera norma, la puerta de acceso hacia sucesivas leyes hasta llegar a la vigente Ley de Procedimiento Laboral de 1995, cuyo inmediato fin perseguido era refundir el conjunto normativo existente hasta la fecha en un único cuerpo legal. El Decreto de 13 de mayo de 1938 -señalaba el Preámbulo de la Ley de 1958-, creador de las Magistraturas de Trabajo, estableció en su artículo segundo que el conocimiento de los asuntos a ellas atribuidos habría de ajustarse a las normas procesales señaladas en el Código de Trabajo, sin otras modificaciones que las que el propio Decreto introdujo. Desde entonces y por sedimentos sucesivos, se ha ido formando un cuerpo de normas de procedimiento laboral con rango jerárquico muy distinto, que es imperioso refundir en un solo texto para facilitar su conocimiento y aplicación por todos los interesados en la relación laboral: Tribunales, Administración, trabajadores y empresarios. La ley de 24 de abril de 1958 sienta las bases para el futuro texto refundido y ordena al Ministerio de Trabajo, oída la organización sindical, la elevación al Gobierno, en el plazo más breve posible, del citado texto y un procedimiento especial para los seguros sociales y el mutualismo laboral acomodado a sus peculiares características (art. 13). El referido texto refundido de procedimiento laboral fue aprobado por Decreto de 4 de julio de 1958 con el fin de garantizar y salvaguardar el derecho de las partes, así como fijar al juzgador la pauta a seguir en la jurisdicción del trabajo. El proceso laboral-se apuntaba en el Preámbulo- está regulado actualmente por normas a las que las partes y el Magistrado han de acomodar su actuación, pero tales reglas se hallan diseminadas en multitud de disposiciones (Código de Trabajo de 1926, Ley de Enjuiciamiento Civil como supletoria, Decretos, Órdenes ministeriales, Reglamentaciones de Trabajo, etcétera) que hacen difícil su conocimiento a quien en estas materias no esté avezado, siendo frecuente observar omisiones de indudable trascendencia para el legislador, ya que tales preceptos, por ser de índole procesal y, por tanto, de orden público, son de ineludible observancia.

Los siguientes dos textos refundidos de procedimiento laboral, el Decreto de 17 de enero de 1963 y el Decreto de 17 de agosto de 1973, se fueron acomodando a las pautas diseñadas por las leyes sustantivas emanadas de la dictadura, hasta llegar a la Constitución española de 1978 y al desarrollo legislativo de su artículo 35. El resultado fue la promulgación del Estatuto de los Trabajadores por la Ley 8/1980, de 10 de marzo, el cual introdujo profundas modificaciones en la naturaleza y contenido de las relaciones laborales. Ello obligó al legislador a acomodar los preceptos de la Ley de Procedimiento Laboral al nuevo ordenamiento sustantivo ${ }^{34}$. Fruto de tal acomoda-

${ }^{34}$ Vide disposición adicional sexta de la referida Ley 8/1980. 
ción fue la aprobación del Texto Refundido de la Ley de Procedimiento Laboral por el Real Decreto 1568/1980, de 13 de junio ${ }^{35}$.

El citado nuevo marco procesal quedó, no obstante, obsoleto tras la aprobación de la Ley Orgánica 6/1985, de 1 de julio, del Poder Judicial, la cual, como señala su Exposición de Motivos, es una de las normas que, en unión de otras muchas, tiene que actualizar el cuerpo legislativo -tanto sustantivo como procesal- español y adecuarlo a la realidad jurídica, económica y social.

La Ley Orgánica del Poder Judicial propició cambios en el orden jurisdiccional social para adaptarlo a la nueva realidad territorial, tanto administrativa como judicial, del Estado. Al crearse por dicha Ley, entre otras instituciones, los Tribunales Superiores de Justicia, como derogación del Tribunal Central de Trabajo, y los Juzgados de lo Social en sustitución, estos últimos, de las Magistraturas de Trabajo, la actualización procesal laboral no se hizo esperar, para lo cual el legislador no propició sin más y como en otras ocasiones el mero cambio de una ley por otra nueva, sino a través de una Ley de Bases (Ley 7/1989, de 12 de abril), que estableció los principios y criterios por los cuales debía guiarse el legislador en una futura regulación del proceso laboral. En desarrollo de tal Ley de Bases se dictó el Real Decreto Legislativo 521/1990, de 27 de abril, de Procedimiento Laboral. Este nuevo texto articulado estuvo vigente hasta el primero de mayo de 1995 , en que entró en vigor el actual Texto refundido de la Ley de Procedimiento Laboral, aprobado por RD Legislativo 2/1995, de 7 de abril, cumpliendo el Gobierno con el mandato contenido en la disp. final 6. ${ }^{a}$ de la Ley 42/1994, de 30 de diciembre («de acompañamiento» a la Ley 41/1994, de la misma fecha, de presupuestos para 1995$)^{36}$.

$\mathrm{Si}$, como se ha manifestado en el párrafo precedente, la Ley Orgánica conllevó la reelaboración del proceso laboral para atender una nueva realidad, y ello supuso, en una sola década, el advenimiento de dos normas de procedimiento (1990 y 1995), no ha ocurrido otro tanto con el profundo cambio experimentado en el proceso civil con la entrada en vigor de la Ley 1/2000, de 7 de enero, de Enjuiciamiento Civil. Una ley esta situada en las antípodas de su predecesora pero con un mimetismo estructural sin precedente con la ley adjetiva laboral.

Sin embargo, tal mimetismo en cuanto a la estructura procesal, esto es, en cuanto a los principios informadores del proceso y del procedimiento, no ha venido acompañado por una correspondiente y obvia sincronización entre las diferentes instituciones de uno y otro proceso. A lo sumo, el legislador de la norma formal civil se ha limitado a edulcorar, a través de una disposición

\footnotetext{
${ }^{35}$ Vide Preámbulo del citado Real Decreto.

${ }^{36}$ Alonso Olea, M.; Miñambres Puig, C y Alonso García, R. M. ${ }^{a}$. Derecho Procesal del Trabajo, Civitas, 11. a edición, Madrid, 2000, págs. 43-44.
} 
final (undécima), algunos aspectos de la Ley de Procedimiento Laboral como mera medida paliativa en lugar de proponer una futura reforma en profundidad de dicho proceso.

\section{La necesaria reordenación del proceso laboral}

El sucinto análisis histórico reseñado en las precedentes páginas, viene a reflejar una constante pugna entre el derecho sustantivo y el derecho procesal. El primero, galopante y abrumador, necesario para dar cobertura a actividades en constante evolución; el segundo, el derecho procesal, a la sombra del sustantivo, a la espera de tutelar los conflictos nacidos de dicha actividad e irresolutos por vías distintas a la contenciosa. Esta «constante pugna» lo ha sido y lo es en buena lid, y los mecanismos utilizados han respondido a las herramientas existentes en cada momento histórico. De esta suerte, y como se ha podido apreciar, siempre y en todo momento ha existido un derecho formal aplicable frente a un conflicto surgido entre partes. Tal derecho formal ha sido el general aplicable a controversias generales (singularmente las civiles) hasta un momento histórico específico y coincidente con la diáspora orgánica de los tribunales encargados de conocer, mediante una jurisdicción especial y mixta, la solución de los conflictos individuales de trabajo. Ello no obstante, es con la última dictadura cuando, de manera decidida, se da entrada a la norma procesal por excelencia.

La expresada norma, la Ley de 24 de abril de 1958, no nace, pese a su Preámbulo, como instituto de refundición de un conjunto normativo disperso, ni para llevar a los aplicadores del Derecho a un texto de fácil comprensión en una materia compleja como lo es la laboral. Admitir todo ello sería tanto como tildar de ignaros a dichos aplicadores además de presumirles desconocedores de la rama procesal por excelencia cual era la civil.

Evidentemente, las razones del legislador de aquella ley eran otras; unas razones más próximas al enaltecimiento de la clase trabajadora única capaz de hacer temblar los cimientos de un régimen ilegal e impuesto por la fuerza. El proceso civil era suficiente, y lo hubiera podido seguir siendo dado, por otro lado, la escasa conflictividad social existente durante los cuarenta años de imposición política.

Pero el legislador de 1958 no confeccionó un modelo paralelo al previsto por la ley formal civil, entre otras razones porque ello no hubiera coadyuvado a justificar la modificación en los términos expuestos en el Preámbulo de dicha ley. El legislador era consciente de ello y buscó horizontes más vanguardistas y fue limando asperezas a lo largo de las sucesivas modificaciones. La ley nació y se fue modificando sobre la base de unos principios procesales y procedimentales capaces de dar seguridad al proceso y agilidad al procedimiento, hasta el punto de ser reclamada su estructura por la doctrina para el proceso civil. 
Así las cosas, y hasta el momento actual, los científicos tanto del proceso civil como del proceso laboral han exaltado las bondades de una ley, la de procedimiento laboral, nacida para acallar suspicacias y rencores de una clase trabajadora sumida en un letargo reivindicativo, pero una ley a la altura de las legislaciones formales civiles más de punta de lanza del entorno europeo más próximo.

Las razones albergadas por dicha doctrina no solo para reconocer las exquisiteces del proceso laboral, sino también para defender a ultranza la especialidad de la materia, pueden ser resumidas en tres cuestiones básicas. En primer lugar, el ser una jurisdicción especializada, consecuencia ello de haber podido desgajarse de sus troncos primitivos, y el ser, igualmente, una jurisdicción implicada en ofrecer al justiciable un proceso rápido y gratuito $^{37}$.

En segundo término, alude la doctrina a la «naturaleza del proceso laboral» como vehículo para privilegiar el proceso laboral mismo y dotarle de autonomía propia ${ }^{38}$, así como de una cierta dosis de especial protección o tutela dispensada al trabajador a lo largo del proceso ${ }^{39}$.

Por último, y como tercera «cuestión básica» apuntada por la doctrina para reconocer las bondades del proceso laboral y defender, con ello, la especialidad de la materia, se apunta a la profunda incidencia de las normas sustantivas en dicho proceso, el dinamismo de aquellas y su enorme diversificación en diferentes ramas dentro de una misma disciplina jurídica. Esta particularidad, se viene a decir, obliga al científico y al aplicador del Derecho a tener muy en cuenta las normas básicas del ordenamiento laboral a la hora de abordar el estudio de las normas procesales ${ }^{40}$.

Las anteriores consideraciones doctrinales circunscritas a las aquí denominadas cuestiones básicas, son marcadamente insuficientes para otorgar al proceso laboral y a su principal norma reguladora, la Ley de Procedimiento Laboral, el valor y el alcance otrora obtenido. Por un lado, y si bien la celeridad del procedimiento viene decidida, en unión del principio de concentración, por la realización de la práctica de la prueba en la fase decisoria y por la eliminación de trámites y diligencias innecesarios a los fines del proceso,

\footnotetext{
37 Cfr. Prieto-Castro Ferrándiz, L. Derecho Procesal Civil, Tomo II, EDERSA, Madrid, 1969, págs. 165-166.

38 Baylos Grau, A; Cruz Villalón, J y Fernández López, M. ${ }^{\text {a }}$ F. Instituciones de Derecho Procesal Laboral. Trotta, 1995, pág. 114.

${ }^{39}$ Montoya Melgar, A. Derecho del Trabajo. Tecnos. 22. a edición. Madrid, 2001, pág. 743.

${ }^{40}$ Albiol Montesinos, I.; Alfonso Mellado, C. L.; Blasco Pellicer, A. y Goerlich Peset, J. M. ${ }^{\text {a }}$ Derecho Procesal Laboral. Tirant lo blanch, 3. a edición, Valencia, 2000, pág. 30. Vide Rodríguez-PiñERo y Bravo-Ferrer, M. et alii, «Proceso de trabajo y justicia constitucional», en El proceso laboral. Estudios en homenaje al profesor Luis Enrique de la Villa Gil, Lex Nova, Valladolid, 2001, págs. 728-729.
} 
ello no obstante se muestra insuficiente. Tal insuficiencia se detecta, principalmente, en factores metaprocesales como lo son la insuficiente dotación económica o la excesiva burocratización de la actividad administrativa de los juzgados y tribunales ${ }^{41}$. Por otro lado, intentar justificar una autonomía propia del proceso respecto del civil es tanto como desconocer la estructura de uno y otro proceso; o, si acaso, sería tanto como no haber constatado la profunda reforma operada por el legislador de la Ley 1/2000, de 7 de enero, de Enjuiciamiento Civil ${ }^{42}$. Finalmente, justificar la pervivencia de la ley actual tal y como está diseñada sobre la base de la incidencia en la ley procesal de las normas sustantivas y su dinamismo, y, además, argumentar la necesaria especialización del operador jurídico en esta disciplina, todo ello es desconocer dónde se residencia el problema de esta compleja rama jurídica. En efecto, la complejidad no se sitúa en la norma adjetiva, sino en las materiales, luego la especialización del operador jurídico lo debe ser respecto de estas últimas y no con relación a la procesal.

La vuelta de hoja a todo lo anterior, esto es, al verdadero nudo gordiano situado en la pervivencia actual de la ley procesal laboral, debe buscarse en la homónima estructura entre dicha ley y la norma procesal civil y, además, descubrir en la situación actual, y con los criterios de supletoriedad de por medio, si en la práctica forense la alternancia de dichas leyes adjetivas crea o no inseguridad jurídica.

En los diferentes períodos históricos analizados con anterioridad, se ha podido constatar, hasta 1958 , la inexistencia de una estructura diferenciada entre la Ley de Enjuiciamiento Civil y otra u otras leyes procesales aplicables a los conflictos laborales, porque -resulta ocioso reconocerlo- la regulación de dichos conflictos a nivel formal quedaba prácticamente reservado a una misma ley procesal. Pero tampoco, y por las mismas razones, cabría esgrimir inseguridad jurídica alguna; si acaso sí le era achacable la lentitud en el procedimiento. Sin embargo, a partir de la indicada fecha, al enuclearse un proceso especial del civil vigente, se ganó en celeridad y en seguridad para el justiciable porque, entre otras razones, la estructura del proceso y del procedimiento se mostraba distinta al comparar ley general y ley especial procesales.

Actualmente, la vigente Ley de Enjuiciamiento Civil tiene una estructura similar a la procesal laboral, si bien esta última, aunque nació vanguardista, ha quedado eclipsada por la ley adjetiva civil. Este oscurecimiento provoca

${ }^{41}$ Alemañ Cano, J. Estructura del proceso laboral. Tirant lo blanch. Valencia, 2008, págs. 139 y 141.

42 Montero Aroca, J. Introducción al proceso laboral. Marcial Pons. Madrid, 2000, pág. 79; vide CRUZ VILlalón, J. et alii, «El limitado alcance de la supletoriedad de la Ley de Enjuiciamiento Civil de 2000 en el proceso laboral», en Nueva Ley de Enjuiciamiento Civil y proceso laboral, Marcial Pons, Madrid, 2002, pág. 92. 
en la práctica forense una gran inseguridad jurídica, y desde el punto de vista teórico produce opiniones encontradas entre la doctrina.

La indicada inseguridad se manifiesta en un gran número de institutos procesales laborales. Diseñar un perfil mínimo y aceptable de todos y cada uno de las instituciones procesales afectadas sobrepasaría con mucho las exigencias impuestas para este trabajo. En esta línea de restricción impuesta, sí es posible reseñar algunos institutos necesitados de una profunda reforma y adaptación a las previsiones ordenadas por la Ley de Enjuiciamiento Civil, tales como la insuficiente regulación de la audiencia al demandado rebelde (art. 183 LPL); la discutida oposición del demandado en el embargo preventivo (art. 79 LPL); el vacío legal existente en torno de las medidas cautelares indeterminadas (727.11. ${ }^{\mathrm{a}}$ LEC) o del juicio de revisión (art. 234 LPL); las mayores garantías ofrecidas al justiciable de adoptarse de manera indiscutida las denominadas diligencias finales (arts. 435 y 436 LEC) frente a las diligencias para mejor proveer del proceso laboral (art. 88 LPL); la dicotómica ordenación de la abstención y recusación (arts. 15 LPL, arts. 5, 221.2 y 221.4 LPOJ, y art. 102.2 LEC); y la mejorable prejudicialidad penal por presunta falsedad documental (art. 86.2 LPL).

No obstante lo anterior, y sin perjuicio de remitir la actual materia a un estudio mucho más profundo ${ }^{43}$, sí, en cambio, puede ahondarse mínimamente en este lugar sobre algunas manifestaciones dominadas por la práctica forense donde se ha podido apreciar una insana confrontación entre las normas procesales, la civil y la laboral, de consecuencias un tanto perniciosas para quienes se sitúan en la labor de aplicar día a día esta rama del Derecho.

En primer lugar, es de resaltar la denominada contestación a la deman$d a$ (art. 86.2 LPL), la cual con una clara correspondencia con un procedimiento informado, entre otros, por los principios de aceleración y concentración, el proceso mismo ganaría en igualdad de armas si tal contestación se llevara a cabo por escrito aun en detrimento, liviano si se quiere, de aquellos principios informadores ${ }^{44}$; porque lo que en realidad produce indefensión no son los plazos, sino su incumplimiento ${ }^{45}$, y tal incumplimiento está fuera del análisis dogmático y no ha de servir para blandir la excusa de una inaplica-

\footnotetext{
${ }^{43}$ En la citada obra, Estructura del proceso laboral, se vienen a analizar, sobre la base de los principios informadores del proceso y del procedimiento laboral, los institutos procesales afectados, la adaptación de la Ley de Enjuiciamiento Civil respecto de la laboral y las carencias de esta última norma (AlEMAÑ CANO, J. Estructura del proceso laboral. Tirant Lo Blanch. Valencia, 2008).

${ }^{44}$ Para una mayor profundización de la tesis sustentada, vide AlEMAÑ CANO, «Estructura...», cit., págs. 123 y ss.

${ }^{45}$ Rodríguez Escanciano, S. Deficiencias del proceso social y claves para su reforma. Marcial Pons. Madrid, 2001, pág. 117.
} 
ción tan intensa de dichos principios según se esté en el proceso civil o en el laboral ${ }^{46}$.

En segundo término, se detecta en el proceso laboral la imposible reparación de errores judiciales plasmados en sentencias recaídas en primera instancia e inatacables en una segunda instancia por imperativo legal (art. 189.1 LPL). Frente a ello, paradójicamente, se tiene por satisfactoria la institución de la nulidad de actuaciones ${ }^{47}$, pese a ser este un instituto contrario a la celeridad del procedimiento y al derecho a un proceso sin dilaciones indebidas ${ }^{48}$.

En tercer lugar, la carencia de un recurso ordinario en la jurisdicción social impide mantener el criterio del doble grado frente a la excepcionalidad de los vigentes recursos. Pero, aun y con todo ello, ni el legislador ni la práctica forense ponen las cosas fáciles al justiciable, pues la exigencia de grabar el desarrollo del juicio -lo cual ayudaría notablemente a la hora de plantear el subsiguiente recurso contra la sentencia dictada- es contemplado en la ley como una mera posibilidad (art. 89 LPL), lo cual contrasta con el imperativo tenor de los arts. 147 y 187 LEC de documentar el desarrollo de las actuaciones ${ }^{49}$.

Por último, y dentro del muestreo propuesto de instituciones generadoras de inseguridad, es en la materia destinada a la prueba donde más se evidencia aquella inseguridad jurídica. Ello es producto, como se ha dicho, de la falta de sintonía entre las dos normas adjetivas, lo cual es altamente perjudicial no ya solo para el justiciable, sino también para quien desempeña la labor de defender o representar a las partes en juicio, por cuanto la carencia de criterios homogéneos puede llevar a un cierto grado de indefensión entre tales defensores o representantes frente a decisiones dispares de los órganos judiciales ${ }^{50}$. Sobre la base de esta línea argumentativa, es de destacar a modo de mera ilustración: a) la parquedad en el tratamiento de los medios de prueba previstos en la ley adjetiva social en comparación con la civil, por lo cual se hace necesario abandonar sistemas de innecesaria raigambre como lo es el acudir de manera sistemática a la supletoriedad y a las constantes interpretaciones encontradas entre la norma suplida y la supletoria; b) la prueba anti-

\footnotetext{
${ }^{46}$ Cfr. Lasaosa Irigoyen, E. La jurisdicción social en España: una visión histórica. Dykinson. Madrid, 2008, pág. 124.

${ }^{47}$ Alemañ Cano, J. Estructura..., cit., págs. 151 y ss.

${ }^{48}$ Aguilera IzQuierdo, R. Proceso laboral y proceso civil: convergencias y divergencias. Thomson-Civitas. Madrid, 2004, págs. 104-105; Gimeno SEndRA, J. V. et alii, Derecho Procesal Civil. Parte general. Colex, 3. a edición. Madrid, 2000, pág. 43.

${ }^{49}$ Respecto del recurso de apelación laboral en los ordenamientos francés y alemán, vide VALDÉS DAL-RÉ, F. Las jurisdicciones sociales en los países de la Unión Europea: Convergencias y divergencias, $<\mathrm{http} / / /$ portal.oit.or.cr/dmdocuments/justicia_laboral/jurisdiccionessocialesunioneuropea.pdf $>$.

${ }^{50}$ Alemañ Cano, J. Estructura..., cit., págs. 106 y ss.
} 
cipada (art. 90.2 LPL), perfectamente regulada y con mayor amplitud en la ley procesal civil (art. 265. LEC); el interrogatorio de las partes (arts. 301 a 306 LEC), más completo y garantizador al reforzar el principio de contradicción; y d) la prueba documental, pues se presenta regulada en la norma laboral con una alta dosis de laconismo (art. 94 LPL), a pesar de la importancia de este medio probatorio tanto en la primera como en la segunda instancia.

Así las cosas, dos alternativas cabrían si no se quiere mantener el estado de incertidumbre generada por la aplicación de una u otra ley procesal, o por ambas, cuando se acuda a criterios de supletoriedad o de complementariedad. Por un lado, y como en el período previo a la entrada en vigor de la primera ley procesal laboral de 1958, la alternativa pasaría por la regulación formal de los conflictos laborales a través de la mera remisión al «juicio verbal» de la Ley de Enjuiciamiento Civil. Esta remisión, ello no obstante, podría ser insuficiente o no encajar de manera decidida al ser el proceso laboral (por razones históricas y por necesidades de propiciar un proceso ágil y de tendencia más protectora respecto del más débil de las dos partes enfrentadas) un proceso investido, entre otros, por el principio de celeridad. Por esta circunstancia, y en evitación de ello, sería deseable la inclusión en la ley adjetiva civil de un único proceso especial destinado a amparar todas y cada una de las controversias nacidas en el seno de las relaciones labora$\mathrm{les}^{51}$. Este proceso especial integrado en la norma procesal civil ${ }^{52}$ sería un proceso cuyo nacimiento, desarrollo (el órgano decisorio podría estar conformado por un juez de carrera ${ }^{53}$, escabinos ${ }^{54}$ o mixto $^{55}$ ), finalización (contra la sentencia debería permitirse un recurso de apelación ${ }^{56} \mathrm{o}$ de apelación restringida ${ }^{57}$ ) y ejecución transcurriera sobre los mismos principios y por idénticos institutos procesales que la Ley de Enjuiciamiento Civil.

La segunda alternativa, por otro lado, capaz de erradicar la tantas veces repetida en este trabajo inseguridad jurídica, conllevaría la elaboración de

${ }^{51}$ En el proceso laboral alemán -Arbeitsgerichtsgesetz- no existen procesos especiales tal y como sucede en el ordenamiento formal laboral español (JIMÉNEZ FoRTEA, F. J. El recurso de casación para la unificación de doctrina laboral -Problemas fundamentales-. Tirant Lo Blanch. Valencia, 1999, págs. 76-77).

${ }^{52}$ Este es el modelo seguido tanto en Italia (los arts. 409 a 447 del Codice di procedura civile italiano vienen destinados a la resolución de conflictos en materia laboral) como en Francia (art. 749 CPCF, vigente hasta el año 2008, pero sustituido por el art. 879 en la redacción ofrecida por el nuevo CPCF y con vigencia a partir de enero de 2009).

${ }^{53}$ Art. 409 en relación con el art. 413 CPCI, y en relación con las normas reguladoras de la organización judicial italiana.

${ }^{54}$ El escabinado es el modelo seguido por el ordenamiento laboral alemán para componer el tribunal de primera instancia ( $\$ 16$ de la Arbeitsgerichtsgesetz alemana).

${ }^{55}$ En este sentido, el Código del Trabajo francés, L. 512-1 y L. 512-8, así como el art. 749 CPCF en relación con el art. 879, vigente, este último, a partir de enero de 2009.

${ }^{56}$ Vide art. 433 en relación con el art. 409, ambos del CPCI.

${ }^{57}$ Vide arts. 78-79 y 543-545 CPCF, y el § 69 de la Arbeitsgerichtsgesetz alemana. 
una ley especial si no se quiere embutir el proceso laboral en la norma adjetiva civil. Tal ley especial, la cual habría de ser muy breve y no contener proceso especial alguno -la Arbeitsgerichtsgesetz alemana ${ }^{58}$-, habría de permitir no solo un proceso ágil, económico y garantizador, sino también posibilitar la indubitada aplicación supletoria de los institutos procesales civiles, incluido el recurso de apelación contra las sentencias dictadas en primera instancia ${ }^{59}$.

${ }^{58}$ El proceso laboral alemán sigue un criterio muy parecido al anotado como segunda alternativa. Vide un interesante comentario sobre el particular en TOPF, H. «El proceso laboral en Alemania: Legislación y jurisprudencia de la ejecución laboral en el derecho alemán», en Congreso de Magistrados del Orden Social: el futuro de la jurisdicción social, obra colectiva. Consejo General del Poder Judicial. Madrid, 2007, pág. 77.

${ }^{59}$ En el proceso laboral alemán cabe la interposición de una apelación [Revision] (§ 69.3, Arbeitsgerichtsgesetz), si bien tal apelación es restringida (( $\$ 69.4$ Arbeitsgerichtsgesetz). 